\title{
La imagen de Dulcinea en el Simbolismo \\ RUSO Y EN Fiódor SOLOGUB
}

José Antonio Hita Jiménez'

Aвstract: The author explains the influence exerted by the novel Don Quixote in Russian symbolism and, particularly, how the image of Dulcinea crosses practically all the work of the major symbolist Feodor Sologub. Taking into consideration the impact caused by the idealist vision of the Cervantes's character in Romanticism, it is understandable that this attracted attention of symbolists or "Neo-Romantics". For that reason, the feminine ideal of Sofia of Vladimir Soloviov, understood as philosophic fundamental of the Russian symbolism, corresponds perfectly with the myth of Dulcinea. Although not mentioning Dulcinea, Sologub shows in his stories how the imperfect of the World kills the pristine beauty. A series of essays, articles and dramas culminate in the symbology of the book The Created Legend ("Tvorimaya leguenda"), where Sologub shows his fundamental idea: the transformation of life through the creator dream. Starting with the Quixote's idealization of Dulcinea, Sologub recreates a World that does not exist but which must exist, that is, Sologub does not offer a rereading of the Quixote, but the novel of Cervantes helps him to elaborate his own artistic creed.

KeYwords: Myth of Dulcinea, Russian symbolism, Sologub.

El Quijote de Cervantes dejó una profunda huella en la literatura rusa. Turguéniev destacó dos tendencias ideológicas en el pensamiento europeo, inspiradas por don Quijote y Hamlet, poniendo a un mismo nivel y encum-

I Professor de Literatura Russa na Área de Filologia Eslava da Universidade de Granada, Espanha. 


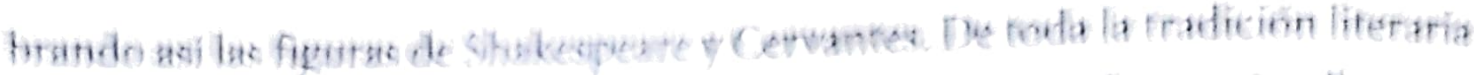

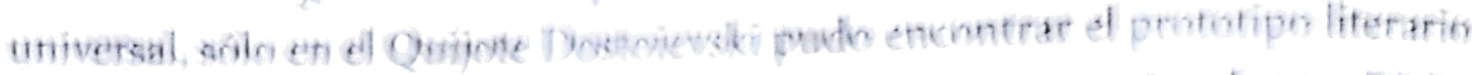

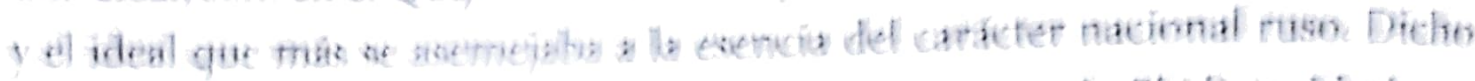

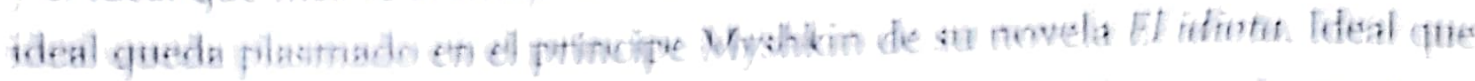

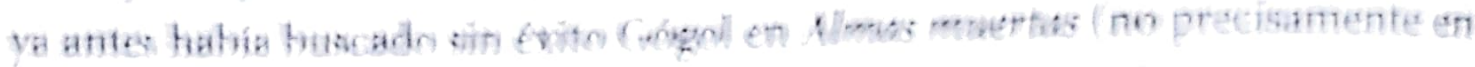

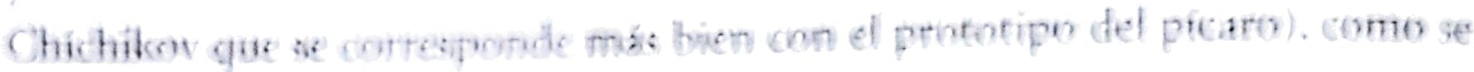

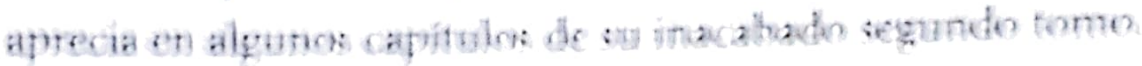

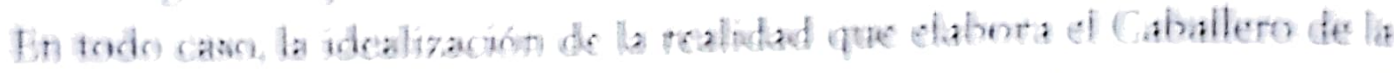

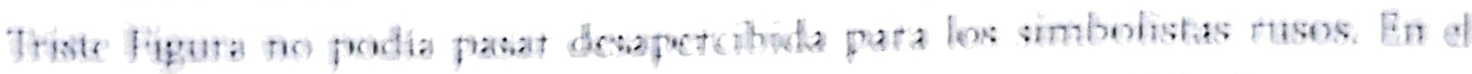

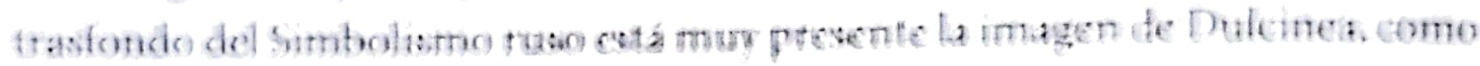

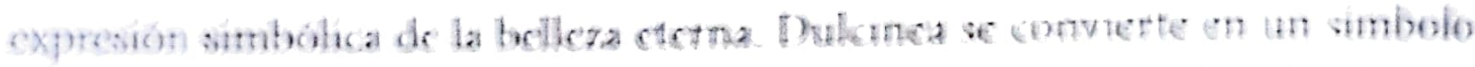

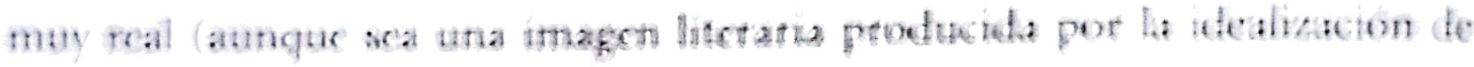

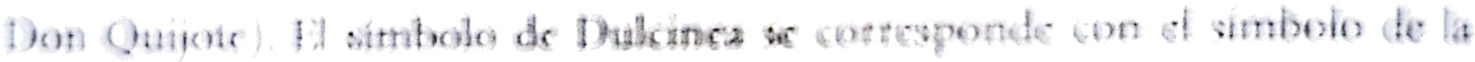

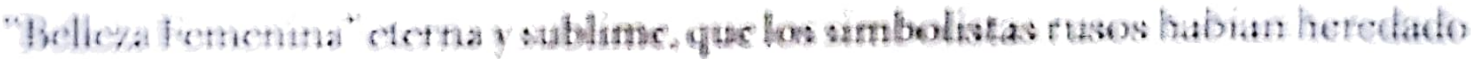

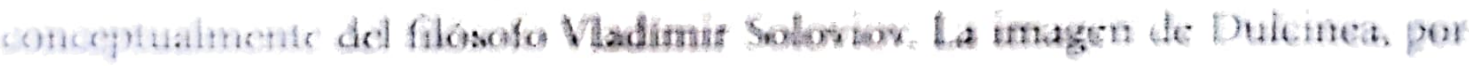

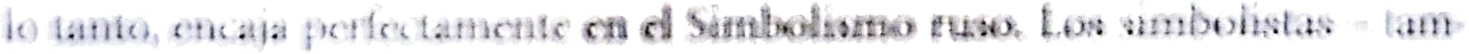

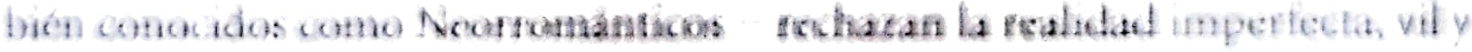

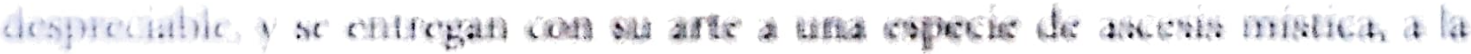

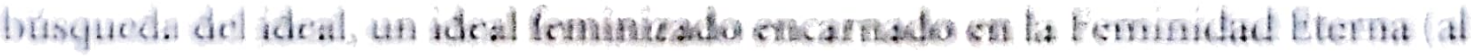

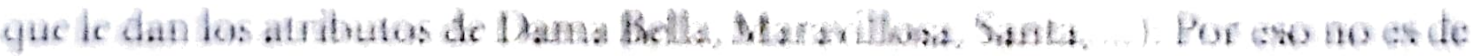

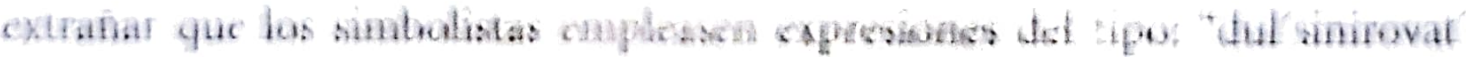

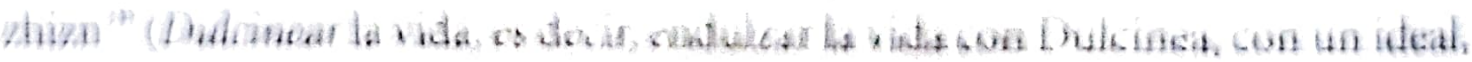

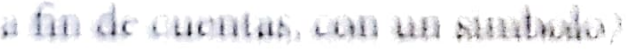

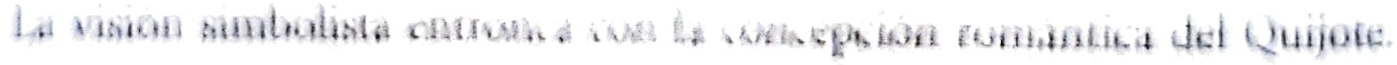

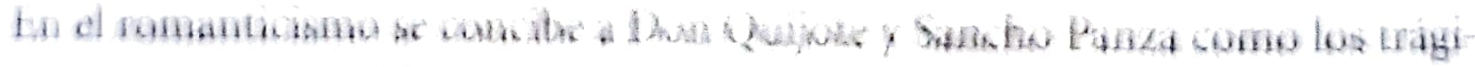

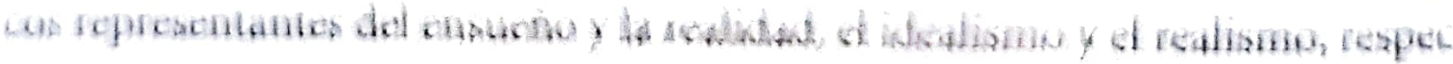

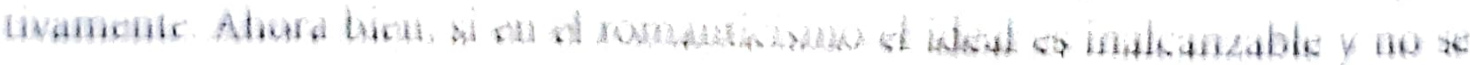

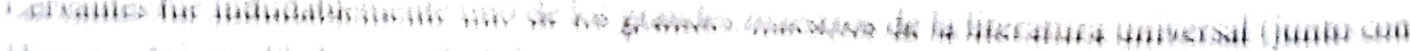

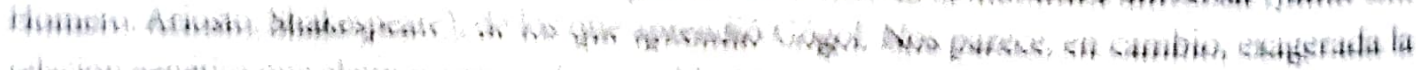

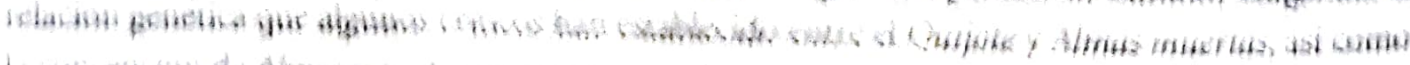

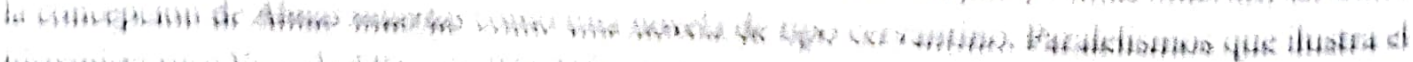

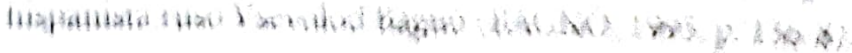


puede conciliar el deseo con la realidad, los simbolistas sí que consiguieron conciliar a uno con otro. Bagnó afirma que los simbolistas están por ello más próximos a la concepción de Cervantes, puesto que "Don Quijote no contrapone la realidad y el deseo", sino que "intenta también forzar a sus próximos a creer en la realidad y la materialidad de sus ideales" (BAGNÓ, 1995, p. 70). Dicho de otro modo, el mundo de ensueño quijotesco sirve para construir una vía de escape a esta terrible realidad, consiguiendo que ese mundo soñado se convierta en algo tan real como la vida misma.

Los simbolistas rusos no nos ofrecen una interpretación del Quijote, sino que la novela cervantina les sirve de inspiración directa o indirecta en su obra. Así, la imagen de Dulcinea atraviesa prácticamente toda la obra de Fiódor Sologub, mientras que se pueden establecer multitud de paralelismos entre la "Dama maravillosa" de Alexander Blok y la bella Dulcinea, a pesar de que Blok no se refiera directamente a ella. Dimitri Merezhkovski (autor del manifiesto del Simbolismo ruso), sin embargo, no se interesó por la idealización de Dulcinea, pues sus reflexiones giran básicamente en torno a los figuras de Don Quijote y Sancho Panza.

Al igual que otros pensadores coetáneos como Berdiáev, Merezhkovski pasa de la concepción social del arte a las tendencias ideológicas propias de las vanguardias. Merezhkovski ve en el Quijote a un profeta de la transformación social de la sociedad, como se revela en el siguiente fragmento de uno de sus primeros poemas:

Reíos gentes, pero puede ser/ que comprendáis en algún momento,/ lo de elevado y sagrado/ que hay en este lamentable Don Quijote:/ Son sagrados en él: el amor y la fe/ ¡Con esta fe se reconfortan/todos los grandes dementes,/ todos los profetas y poetas! (MEREZHKOVSKI, 2000, pp. 188-9)

En su artículo "Don Quijote y Sancho Panza”, el crítico ruso clestiona que el Quijote esté preparado para el autosacrificio por el exceso de racionalidad que le lleva a actuar, pues mide y sopesa las posibles consecuencias de sus acciones dejando entrever más que un comportamiento altruista "una enfermiza y absurda sed de hazañas" (MLREZHKOVSKI, 1889, pp. 13-4). La 
interpretación social de la novela le conduce a Merezhkovski a considerar más importante la figura de Sancho Panza que la de su amo. En todo caso, las contradicciones no abandonan a Merezhkovski en el citado artículo y en su libro Eternos compañeros de viaje, oscilando entre la concepción populista y la mística del simbolismo. ${ }^{3}$

Aquí nos centramos principalmente en el análisis de la obra de Fiódor Sologub, teniendo en cuenta que la concepción simbolista de Dulcinea sólo se puede entender en el ámbito de las ideas de Vladímir Soloviov.

Todos los simbolistas rusos parten de la doctrina de Sofía de Soloviov. Sofía es el espacio primordial, el más elevado que tiene la naturaleza humana. Es el espacio en el que la divinidad comienza a manifestarse. Sofía es, por tanto, la forma primera que recibe pasivamente la Gran Idea sobre el Universo que emana de Dios, de la luz divina. En ella (Sofía) está encarnada la plenitud inicial de la vida. Su esencia está oculta y es inefable; su esencia es como el alma humana: invisible, imperceptible, es decir, no puede ser expresada. Solamente es posible expresar su símbolo. ${ }^{4}$

Se trata habitualmente de símbolos que conllevan la idea de la luz. Todo lo que es luminoso (las estrellas, el sol, las velas, las lámparas) también se presenta ante Soloviov como la imagen de una "Mujer Bella".

Soloviov tuvo una revelación mística durante su estancia en Egipto; en el cielo se le apareció el rostro de una mujer de gran belleza que abarcaba toda la tierra, los mares, ríos, bosques y nevadas montañas. Visión que nos transmite el amanecer del primer día de la creación. Estamos hablando del conocimiento místico (San Juan de la Cruz y Soloviov se nutren de la misma fuente). De esta manera mística se reveló a Soloviov que la primera esencia del mundo era la 3 Como acertadamente subraya Vsevolod Bagnó en su artículo “Don Quijote visto por Merezhkovski”
(BAGNO, 2005).

4 El "símbolo" es el elemento único para expresar la quintaesencia, lo elevado y sublime del más allá (idea kantiana). El símbolo está oculto y ha de ser desvelado y revelado por el poeta, el único que posee una percepción y sensibilidad especial. Si el símbolo en sí está oculto en las profundidades del mundo, en cambio sus destellos se difunden por los fenómenos externos de la tierra (idea
platoniana). 
intachable belleza, la forma llena de contenido divino. ${ }^{5}$ Es el alma viva, sublime y omnipresente de la naturaleza, del universo y de la humanidad en general. Sofía es "la forma superior" que "une con Dios todo lo que existe".

En el devenir de la historia humana, tras el pecado original, el alma universal queda enturbiada pero no desaparece, sino que pervive y se manifiesta tanto en los fenómenos bellos de la vida natural como en la vida humana. Según Soloviov, la belleza de la naturaleza es objetiva, existe en realidad, no en apariencia. Lo que estamos viendo son los ecos, los destellos de esta invisible perfección, de esta apenas perceptible armonía.

La belleza llena de plenitud nuestras almas. En algunas mujeres hay huellas de esta belleza espiritual. En la mujer que amaba - una mujer casada - veía Soloviov la encarnación de esa belleza espiritual. Esta materialización de la bella imagen femenina (a Blok le ocurre lo mismo con su futura mujer Liubov Mendeleeva) forma parte de la sensibilidad del poeta, que no de la concepción ideológica del simbolismo. Sofía es algo femenino. No es extraño que sea la mujer la portadora de esta belleza.

Como el alma está contaminada por la imperfección y la maldad, la misión del poeta (y de la humanidad) es recuperar esta esencia divina del Cosmos para llegar a alcanzar la "Humanidad Divina" (hay que recuperar esta imagen de la perfección divina). Soloviov creía en la posibilidad de que en un futuro se recuperaría dicha esencia y la humanidad llegaría a una nueva etapa de su evolución: la "Humanidad Divina". Soloviov confiaba en la gran transformación de la naturaleza humana.

5 K. Mochulski desmiente la versión oficial sobre los motivos del viaje de Soloviov a Egipto supuestamente por razones científicas (estudios filosóficos, de la Cábala o de la lengua árabe); en realidad, Soloviov presentía el encuentro místico con Sofía. Mochulski se basa en el poema Tres encuentros ("Tri svidania"), compuesto veinte años después de su viaje, donde Soloviov describe cómo se le reveló la "imagen de la belleza femenina", es decir, el fundamento divino del mundo (MOCHULSKI, 1995, p. 95-102).

6 En su artículo sobre Auguste Comte, Soloviov nos dice de Sofía que ese Gran Ser femenino "sin ser Dios, ni el Hijo eterno de Dios, ni ángel ni santo ... no es otro cosa sino la humanidad verdadera, absoluta y plena, la forma suprema que lo engloba todo, el alma viva de la naturaleza y del universo, eternamente unida, la que se une con Dios en el proceso de evolución y la que une con Dios todo lo que existe" (SOLOVIOV, 1990, T. 2, p. 577). 
En el mundo - en el que se encuentra Soloviov - sí que se puede hacer algo, es decir, se pueden plasmar imágenes, destellos de la Belleza eterna que es inherente a la naturaleza. Sólo hay que evocar estas imágenes, darles vida, darles forma y, por supuesto, luchar contra todo lo que perjudica, hace daño y estropea esta bella imagen de Sofía.

Tanto Blok como Sologub están cumpliendo con esta misión. El primer ciclo lírico de Blok (Pocmas sobre la Dama Maravillosa) constituye la presentación de la imagen de "Sofía" a través de los símbolos (imágenes de la luz). ${ }^{7}$ Sologub muestra al principio lo contrario: el mundo es tan imperfecto y corrupto que acaba con la belleza prístina y pura, asesina la belleza y deteriora lo bello.

La imagen idealizada de Dulcinea atraviesa prácticamente toda la obra de Fiódor Sologub (relatos, ensayos, novelas, dramas), aunque sólo en ocasiones aluda a la heroína cervantina.

En los relatos de Sologub no se menciona a Dulcinea, pero sí que se suele reflejar en ellos cómo el mundo imperfecto deteriora y asesina lo bello.

En el relato El gusano ("Cherviak") (WEB, rasskazy.cherviak, pp. 1-18), ${ }^{8}$ la protagonista es una joven llamada Vanda, que rebosaba belleza física y espiritual, y plenitud. Vanda sufre una transformación radical en la nueva casa donde se aloja para continuar sus estudios. Su imagen y su alma se van deteriorando paulatinamente hasta que llega a desmoronarse por completo cuando el dueño de la casa le dice que lleva dentro un gusano que acabará devorándola. El gusano es el símbolo de lo vil y despreciable ("poshlost'”), es decir, de aquello que destruye la belleza.

En otro relato de Sologub, La belleza ("Krasotá"), Elena, que en su desnudez nos revela los destellos de la belleza celestial, quería que la gente entendiese

Entre la imagen de Dulcinea y la Dama Maravillosa de Blok se pueden establecer multitud de paralelismos, de los que prescindimos para centrarnos únicamente en la obra de Sologub.

encontrado suficiente material para esta investas completas de Sologub en ruso, aunque hemos

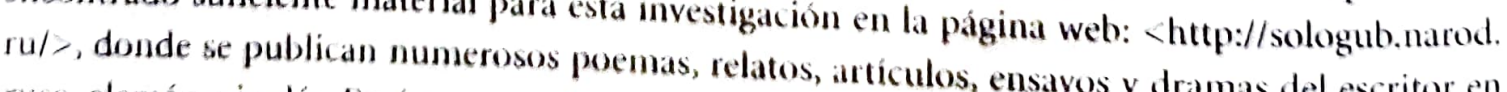
ruso, alemán e inglés. En ésta y sucesivas citas a dicha píginas, ensayos y dramas del escritor en ción y del documento citado. 
que hay un "objetivo en la vida": la belleza encarnada en su madre. Desvelar esta belleza - destellos - debe ser el objetivo, la aspiración del escritor y de todos los seres humanos. Dicho de otro modo, restaurar la belleza para construir un mundo mejor.

A Elena le gustaría que todas las personas llegasen a ser en algún momento como ella ( su madre: tranquila, maravillosa y veraz - Nota del A.) para que comprendiesen que sólo hay un objetivo en la vida: la belleza, y se construyesen una vida digna y sabia. (SOLOGUB, 1990, p. 288)

Nos sorprenden los destellos de las luces mientras se desnuda: "Los destellos de las lámparas y de las velas recorrían su piel y alegraban a Elena", "su imaginación femenina" y sus "alegres sueños sobre la dicha" (SOLOGUB, 1990, p. 288). La belleza física y espiritual de Elena se perturba con la aparición de Makrina. Su paz, docilidad y tranquilidad se contaminan con pensamientos perversos y viles.

La salvación individual no es posible en un mundo donde todo está interrelacionado, del que todos somos responsables ("Ves' mir vo mne"). Hay que aspirar a la Belleza Universal (a la salvación de toda la humanidad), pero esto no es posible, aparece como algo utópico. Elena comprende que en el mundo impera el vicio y la perversión; razón por la que debe ser castigado e incluso destruido. Elena propone una "solución": "Hay que condenarlo (al mundo) a muerte, y a mí misma con él" (SOLOGUB, 1990, p. 292). Una vez ha llegado a esta conclusión, Elena se suicida.

En el relato autobiográfico Sueño sobre las piedras ("Mechtá na kámniaj") (SOLOGUB, 1990, pp. 332-9), Grishka - huérfano de padre sastre y atormentado por su madre la cocinera - huye de su vida terrible, fea y grotesca refugiándose en los sueños. Grishka vive para soñar, los sueños lo trasladan a un mundo lleno de gozo, paz y tranquilidad espiritual, aunque una y otra vez ha de volver a la cruel realidad que le depara tormentos y penurias. El protagonista pretende tomar conciencia de sí mismo, encontrar y aprehender su lugar en el mundo, pero la reincidente pregunta "¿quién soy yo?" no obtiene respuesta.

En este relato se plasman los principios de Sologub sobre la estética del sueño. En su artículo "Istética del steño" (WLB, statiesse.esteticamechty, 
pp. 1-4), ${ }^{9}$ el escritor simbolista explica cómo ha de ser la obra de arte y en particular la creación teatral, debido a las posibilidades de catarsis que ofrece el teatro. La obra ha de provocar en el espectador el ensueño. El espectador no ha de ver en la escena lo que está habituado a ver en la vida, sino algo que estimule su imaginación y le dé rienda suelta, que libere su imaginación y le permita sumergirse en otro mundo, en un mundo de ensueño (ideal y fantástico). La estética del sueño toma su material de la realidad, pero sabe combinar fácil y libremente los elementos de la realidad, de manera que las creaciones del sueño poseen una fuerza suprema de convicción y el más elevado valor artístico. Incluso los malos sueños - afirma Sologub - trasladan al alma una tranquilidad y luminosidad que difícilmente transmiten otras artes. Sologub incluso cree que "La gente sería bastante más feliz y más rica espiritualmente si supiera que el sueño es también una actividad creadora, como cualquier otro arte" (WEB, statiiesse.esteticamechty, p. 3).

Aunque Sologub no habla aquí de fuentes literarias, parece obligada la reflexión: ¿Acaso no es este mundo de ensueño el que fortalece y alimenta las ganas de vivir de Don Quijote e incluso lo mantiene vivo en los momentos de flaqueza? ¿Acaso no está viva la imagen de Dulcinea del Toboso, producto de la fantasía del Quijote, y acaso no se ha perpetuado gracias a la literatura? ¿Acaso no ha dado rienda suelta a la fantasía del lector universal una historia real y aparentemente "ordinaria" pero tan bien narrada?

A conclusiones radicalmente opuestas a las de Elena parece llevarnos el relato Lielka, historia de un niño que recita de memoria poemas y los compone a escondidas de su padre. Las preguntas sin respuesta del narrador (tras las que está el propio autor) planteadas en relación con la tensión que expresa el rostro de Lielka (“ ¿No será prematura está tensión? ¿No será infructuosa? ¿O precisamente esta fuerza, que pretende encontrar una salida mediante una actividad libre, es la fuerza que vencerá las dificultades?") (SOLOGUB, 1990, p. 250) desembocan en una idea crucial: quizás la fuerza de este niño ante la adversidad nos indique el camino a seguir; la lucha tiene sentido - por más inútil que parezca - para construir un mundo mejor.

9 Publicado, además, en la revista Teatr i iskusstvo. 1915. No 5. 1 fevralia. 


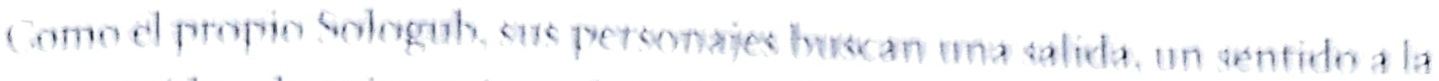

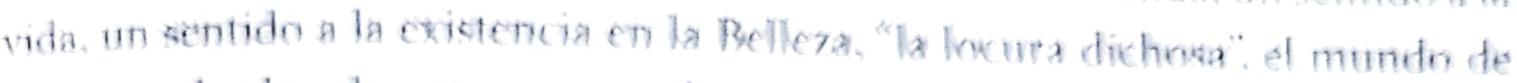

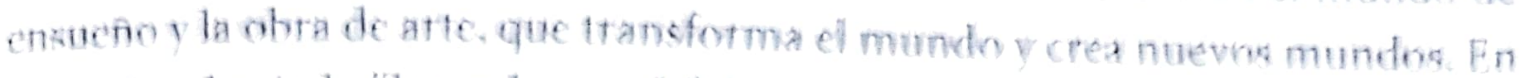

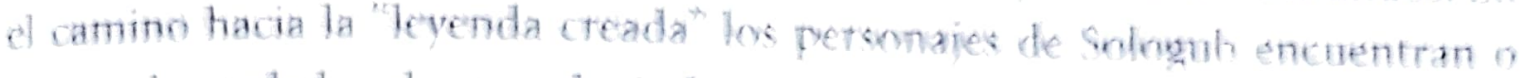
huscan la verdad y el consucto (satvo excepciones como Vania v Kolia en Fl

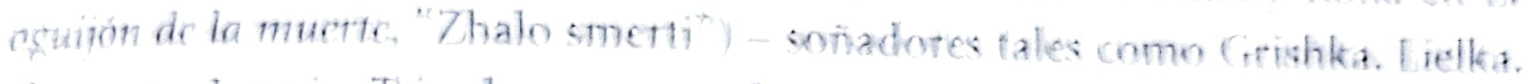
e) maestro Loquin, Tritodow,

y cada uno encuentra en este camino su pas magico, matavilloso, su Tutandina o hada madoma.

Wha serie de ensayos, atticulos y dramas desembocan en las smbologita del litro La Leyenda creada ("T vorimaya lcgucnda"). En todos. Sologub pretende

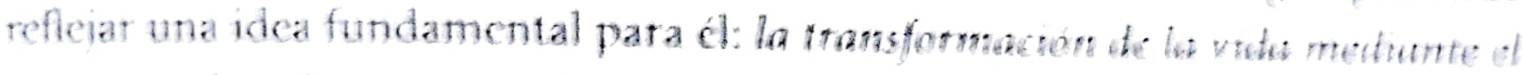

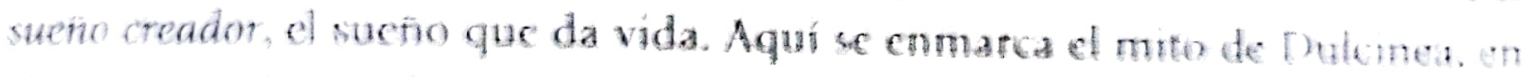

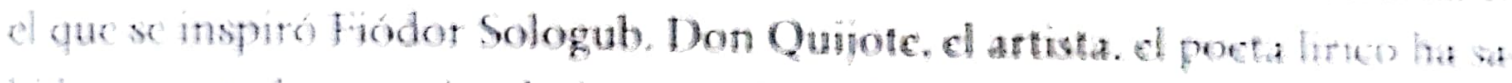
bido creat todo ut mito, la imagen de Dulcinca. valiendose te un matertat rustico y ordinario. Al artista esta obligado a treat lo gite no sxiste perto que

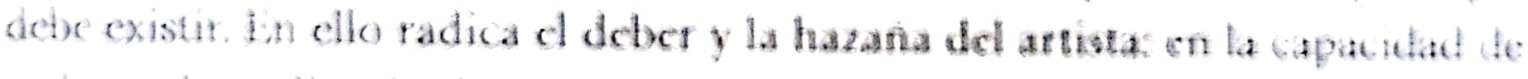

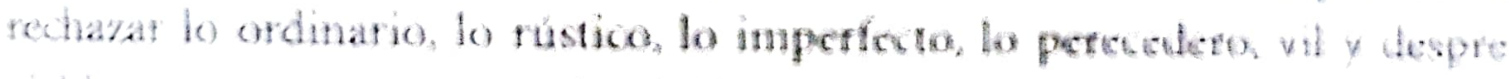

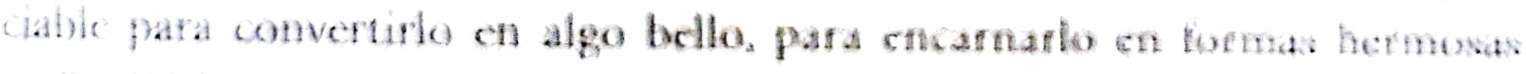
BAGNO, 1495, Pf, $70-1)$

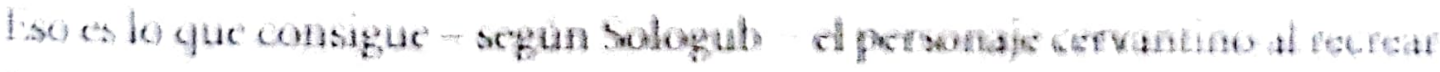

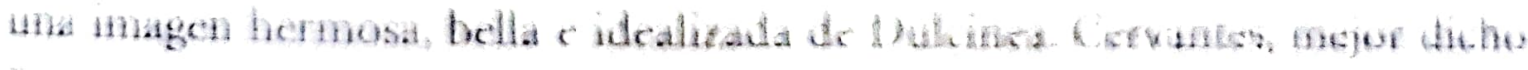

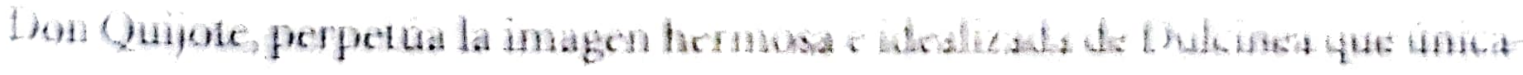

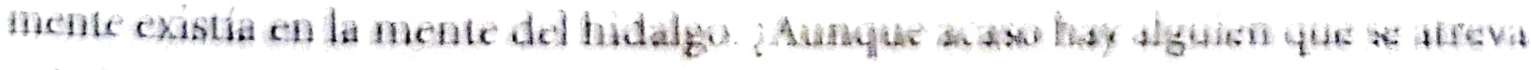

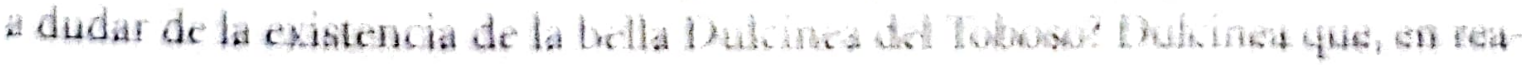

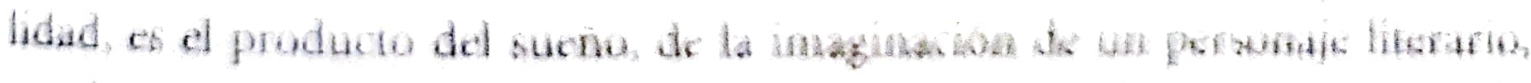

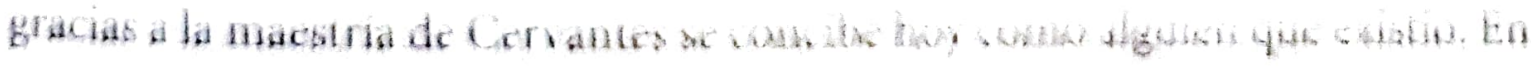

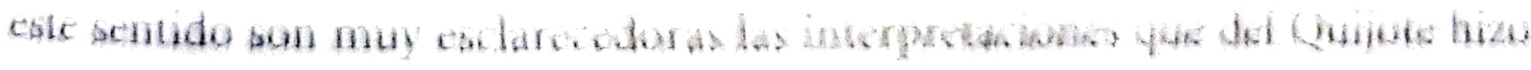

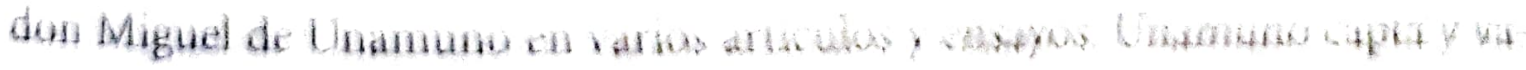

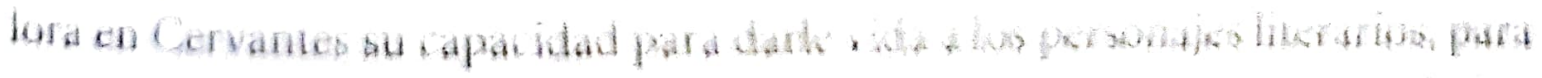

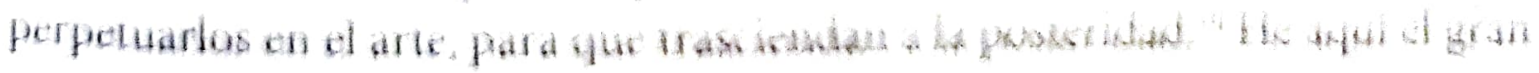

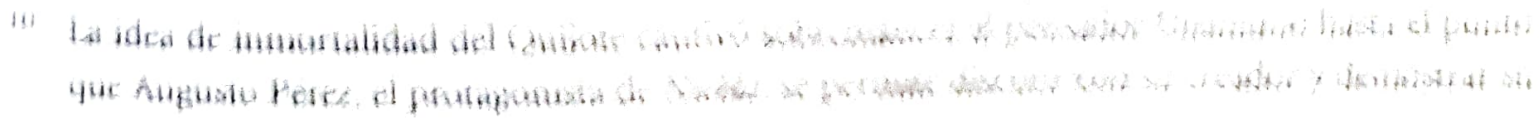


hallazgo de (ervantes (el hecho de dar vida a la imagen sonada), en el que se inspita Fiodor Sologub para plasmar su concepción de la vida y del arte.

Ya hemos visto que los personajes de Sologub se suelen refugiar en el sueño (Vanda, Grishka); el mundo de ensueño les sirve para evadirse de la terrible realidad. De ahi vicne su concepción de la estética del sueño. El escritor, el artista, en general, debe crear el mundo que no existe pero que debe existit. Ese es su deber y en alcanzar dicho ideal se halla su mérito, su hallazgo. Asi deben entenderse los planes del Sologub poeta para recrear y reencarnar, al igual que hizo el Quijote con Dulcinea, su "leyenda creada".

Cómo se refleja el concepto de "leyenda creada" en sus ensayos y artículos hasta desembocat en la novela homónima?

En el ensayo El cnsucno de Don Quijote, Sologub dice:

Al rechazar a Aldonza como Aldonza y aceptarla como Dulcinea, Don Quijote realiza la hazana lírica. No se trata de Dulcinea soñadora, sino de la que se llama Aldonza. Según otros la linda y bruta joven, para mi es la más hermosa de las damas (WIB, osologube, p. 160).

Se trata de la transformación de la vida por el arte simbolizada en la imagen de Dulcinea creada por Don Quijote. Su mêrito consiste en crear la her mosura y perpetuarla para siempre, valiéndose de un material ordinario v descolorido. Continúa Sologub:

Es ciertanente hermosa, porque no se rata de la belleza ya hecha, acabada, decadente, sino creada y viva para siempre. Don Quijote, verdaderamente sabio, en sus intentos de crear la hermosura ha elegido el material menos trabajado, que deja el campo mas libre posible para el creador (op. cic. V. BACNO, 1495, p. 70).

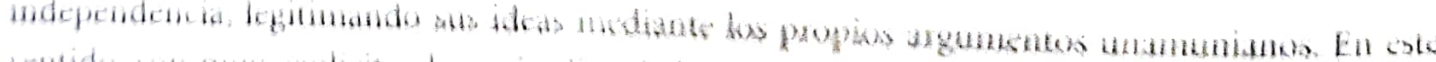

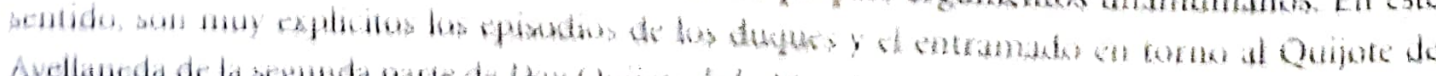

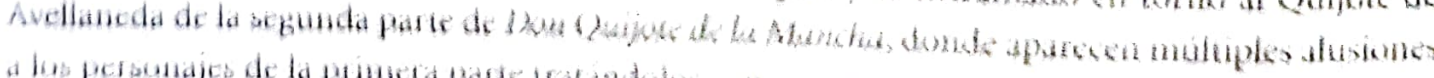

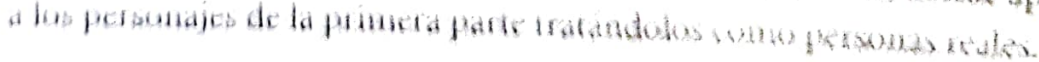


A Sologub le interesa más el personaje literario que su autor, pues en este ensayo no menciona a Cervantes. Don Quijote es como el poeta lírico capaz de transformar lo terreno, pasajero y perecedero (Aldonza) en algo hermoso, trascendental y eterno (Dulcinea del Toboso).

En el artículo "Los demonios de los poetas" ("Demony poetov") Sologub distingue dos extremos que definen la poesía: el lírico y el irónico. Para explicar esta visión dualista de la poesía, Sologub se inspira nuevamente en el Quijote de Cervantes y su ideal: Dulcinea, que ante los demás aparece como la aldeana Aldonza. Don Quijote es concebido como el poeta lírico y Sancho Panza como el poeta irónico. Para el Quijote no existe Aldonza pero sí Dulcinea, mientras que para el poeta irónico (Sancho Panza) no existe Dulcinea y sí que existe Aldonza. Dice Sologub:

Don Quijote - poeta lírico - ángel que dice a la vida siempre no: debe erigir sobre la momentánea y casual Aldonza otra imagen querida y eterna. Lo dado ... se transforma y sobre la ordinaria Aldonza se eleva la eternamente maravillosa Dulcinea del Toboso... Con el esfuerzo lírico se Dulcinea el Mundo. El ámbito de la lírica, de la poesía que rechaza al mundo, es el ámbito sagrado de Dulcinea (WEB, stati.demony, p. 4).

Sologub se refiere así a que Dulcinea es el ideal, el sueño, la poesía que se distancia del mundo, lo niega, lo rechaza y lo transforma, crea un nuevo mundo, éste sí, lleno de sentido y de plenitud.

El símbolo dualista Dulcinea/ Aldonza se refleja nuevamente en la pieza teatral La victoria de la muerte ("Pobieda smierti") (1907) (WEB, piesy.pobieda, pp. 1-25). En el prólogo aparece Dulcinea, llamada por todos Aldonza, cuya hermosura no es apreciada ni por el poeta ni por el rey. Aldonza aquí es llamada y reconocida como la reina Ortrudá. El poeta no reconoció a Dulcinea que portaba pesados cubos, y esperaba verla con zapatos bordados de perlas. Dulcinea necesita que su hermosura sea amada, cantada y coronada (v. BAGNO, 1995, pp. 71-2). Con el objeto de perpetuarse, decide reencarnarse en la esclava Alguista."

1) Bagnó se limita en su análisis al prólogo del drama, donde únicamente aparece bukinea. La referencia a Alguista y la inclusion de esta historia trasciende el mito de Dukinea y complica 
Sologub se inspita en la leyenda recogida por Potanin en el libro Motivas orientales, donde se nos narra la leyenda de la reina Berta Patalarga, madre de Carlo Magno. '2 Sologub conserva el nombre de Alguista, no el de otros personajes, introduciendo algunos cambios. Tras el engaño, encantamiento de Alguista, y la conspiración con su madre Marguista, Berta es llevada al bosque. Cuando aparece el hermano de Berta para que se sepa la verdad, Alguista, desconsolada, decide confesarse culpable ante la oposición de su madre, y finalmente muere con su hijo no sin antes el rey reconocer amarla a ella. Por arte de encantamiento, Alguista convierte al rey y a su reino en piedra.

La penúltima frase del drama "Vence el Amor con la Muerte" resulta lapidaria. El Amor que siente Alguista vence, trasciende, se perpetua. También vence Dulcinea (ésta es "su última victoria"), consecuentemente, al haberse reencarnado en la esclava Alguista. Alguista ha realizado la hazana encomendada por Dulcinea. A esta conclusión nos lleva Sologub tras modificar la leyenda de la reina Berta.

De manera que la transformación de la vida mediante el sueno creador es una hazana alegre y difícil. Is éste el tema principal de la obra de Sologub: la leyenda creada. A estas ideas Sologub les dio forma literaria en su novela La leyenda creada ("T vorimaya leguenda"). Trilogia escrita entre 1905 y 1913. 1lamada al principio Los hechizos de Navi ("Navii chary"). La primera parte se citulaba La leyenda creada (1906), a la que se unieron las novelas Gotas de sange ("Kapli krovi"), La rema de Ortruda ("Koroleva Ortruda") y Humo y ceniza ("Dym i pepel") (1907-1913). Más tarde, Sologub llamaria a este ciclo

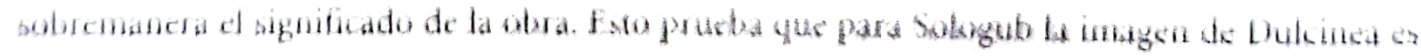

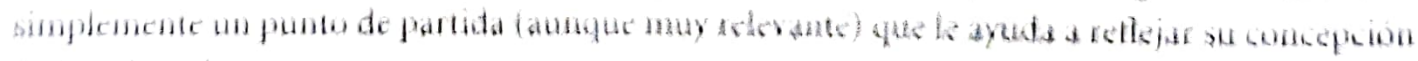
de la viday elarte

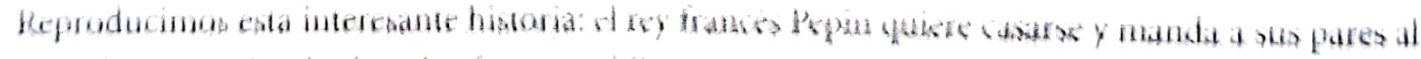

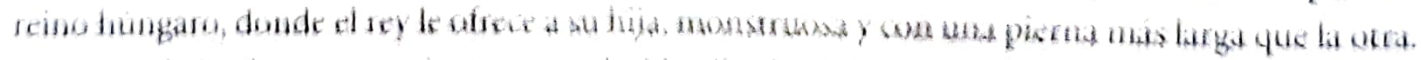

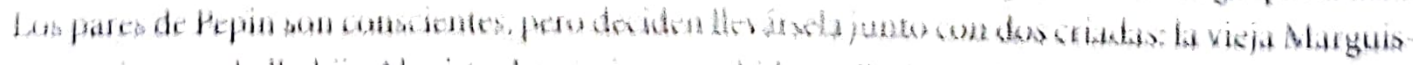

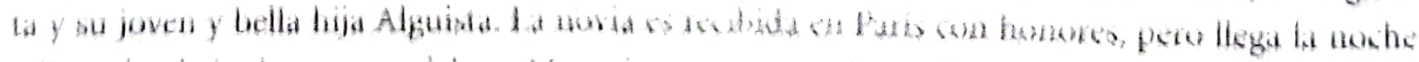

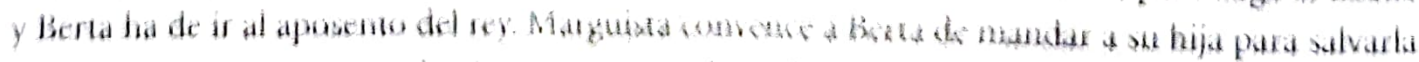

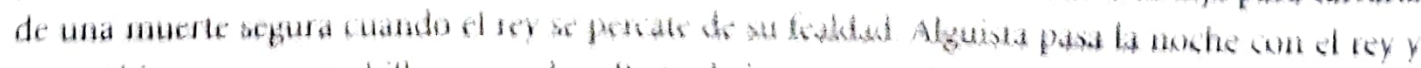

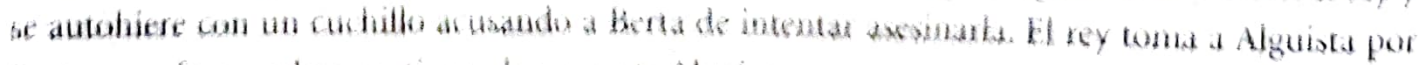

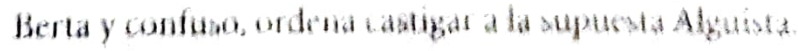


de novelas La leyenda creada, título que coincide con la idea original de la novela. El autor crea una leyenda, al igual que Don Quijote, inspirándose en un material ordinario y pobre. La novela comienza así: "Cojo un trozo de vida, ordinaria y pobre, y creo con ella una dulce leyenda, pues soy poeta... sobre ti, vida, yo, el poeta, erigiré mi leyenda creada sobre lo encantador y maravilloso" (WEB, romany.kapli, pp. 1-145).

Con estas líneas, como si de un epígrafe se tratase, empieza Gotas de sangre. La acción de la novela comienza en un lugar paradisíaco, donde se instala el químico Trírodov y donde consigue plasmar sus ambiciosos planes al crear una colonia habitada por niños dóciles y tranquilos, llenos de vitalidad y energía positiva. Trírodov entiende que hay que matar la fiera en el hombre y liberar aquello que se le concedió en sus orígenes: lo verdadero humano, lo divino. En la ciudad corren rumores sobre Trírodov, dándole mala fama y la policía interviene. Aparece en la escena el mundo de los enfurecidos o salvajes, el mundo de los arrestos, traiciones, persecuciones y asesinatos. Amenazan con cerrar la escuela, acusan a Trírodov y todo lo que en su colonia es maravilloso lo tachan de criminal. Trírodov y su amiga Elizabeta unen sus corazones con las almas de gentes de otro país. Se nos transmite que el milagro está en la voluntad y en la libertad.

La segunda parte (La reina Ortrudá) trata sobre una reina de las Islas Baleares. Se mezclan la fantasía medieval y la actualidad: los príncipes, la aristocracia, los socialistas y miembros del parlamento están ocupados con sus pequeños quehaceres. Los tormentos de la reina llegan al corazón Universal de Trírodov. Muere la reina pero la voluntad de las gentes de las Islas adquiere una fuerza inmensa gracias a Trírodov que es coronado como el rey Gueorgui.

En La leyenda creada se reflejan los colosales planes de Sologub, marcando un rumbo parecido al que siguieron Ye. Zamiatin y $\mathrm{M}$. Bulgákov en sus novelas. A pesar de haberse reeditado en tres ocasiones, la obra sigue siendo poco estudiada e incomprendida."

13 La primera en apreciar el significado de esta trilogia fue su mujer Anna Chebotariévshilya en el artículo "La obra creada" ("Tvorimoe tworchestvo"), publicado en la revista til eppectudor (ZRTTEL', No 2, 1908). Cita sacada del documento Solore Sologub (WLB, osologube, p. 68). 
El poeta Sologub cumple así con su deber y obligación de artista, al crear una leyenda que transforma la vida, que la redime. Al igual que Don Quijote hizo con Dulcinea, Sologub recrea un mundo idealizado y de ensueño que, en realidad, no existe pero que debe existir.

La visión de la realidad como algo que debe ser transformado se complementa con algunas declaraciones de Sologub en su artículo "Sobre el Simbolismo" (WEB, osimbolizme), donde el escritor defiende las elevadas aspiraciones de los simbolistas. Sologub entiende que amar la vida porque sí es ingenuo y absurdo. En la vida hay mucho de maravilloso, pero también de despreciable, detestable, que debe ser odiado con todas las fuerzas del alma. No hay que amar la vida tal y como es, porque merece ser transformada, cambiada. Dicha transformación sólo llega a través del arte, de la voluntad creadora del artista/ poeta.

La negación de la realidad, de ese "mundo terrible" - por el que abogan Sologub y, en general, los simbolistas rusos (Blok, Biely, etc) - y la evasión o huida de la realidad en busca de un refugio en el arte es una actitud o postura que ha sido condenada de socialmente poco comprometida, individualista o antisocial. Frente a tales acusaciones, Sologub se defiende arguyendo que los simbolistas no son individualistas ni antisociales, como se les trata habitualmente, pues ellos aspiran en última instancia a la Unión Universal ("Vseedinstvo", término de Soloviov), a la salvación del hombre y del mundo. Sólo que esa búsqueda exige el refugiarse en sí mismo, en su "yo", en su libertad individual para alcanzar la ansiada fusión con el mundo.

En este sentido resulta muy elocuente su poema: "Yo soy el dios del mundo misterioso/ Todo el mundo se ubica en mis sueños/ No me crearé un ídolo/ $\mathrm{Ni}$ en la tierra ni en el cielo" ("Ya bog tainstvennogo mira/ Ves' mir v odnij moij mechtaj/ Ne sotvoriu sebe kumira/ Ni na zemlie, ni v nebesaj"). Como representante del simbolismo, Sologub creía en el lugar especial que ocupa el poeta entre Dios y el mundo.

Sería erróneo buscar en la obra de Sologub una interpretación o relectura del Quijote. La novela de Cervantes le sirve de inspiración al simbolista mayor ruso para elaborar su credo artístico, su manifiesto literario. Concretamente, la idealización de Dulcinea que llevó a cabo Don Quijote marcó profundamente gran parte de la creación literaria de Fiódor Sologub. 
Referencias bibliograficas

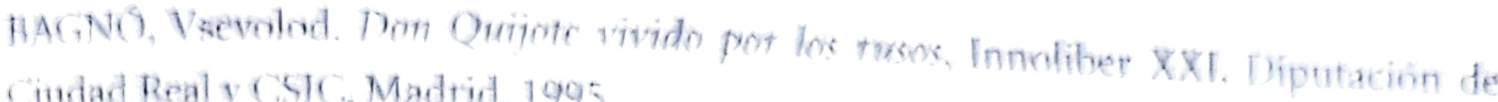
ciudad Real y CSTC Madrid, 1905.

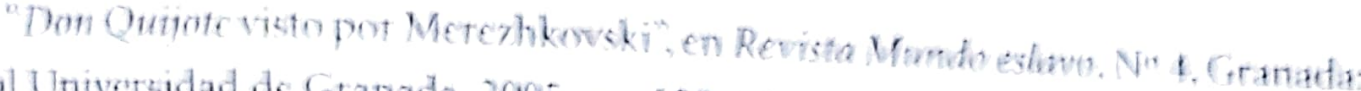
Fditorial Univeraidad de Granada, 2005. . . 157.6.

MEREZHKOVSK 1. 1)imitr. "T)on Qumot is Sancho Panda". en Severm vestmik, 8. 1880 (1) $, 13,4$

Stipotyotenia i poemy, Sankt-Peterburg. 2000.

MOCHULSK], Konstantin. "Vadimit Solowiow 4. Puteshevive v Iondon : Estpet"

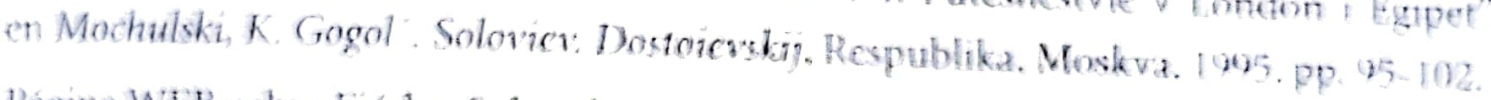

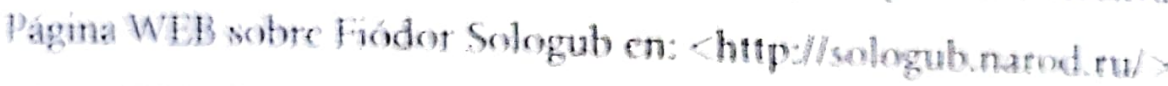

SOLOGUB, Fodot. Tiazholye Sny. Roman. Rashaty. Leningrad: ludeshestvennays literature, 1990

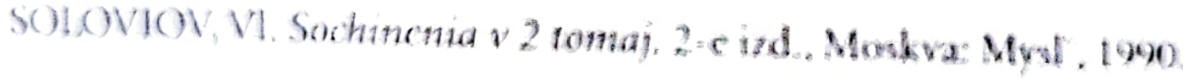

